\title{
DAMPAK PENGETAHUAN AKAN MANFAAT ASI TERHADAP KEMAMPUAN BICARA PADA BAYI 0-24 MINGGU
}

\author{
Agus widodo \\ Program Studi Fisioterapi Fakultas Ilmu Kesehatan/ \\ Universitas Muhammadiyah Surakarta \\ Surel: aw290@ums.ac.id
}

\begin{abstract}
ABSTRAK
Stimulasi visual sangat erat akan kemampuan berbicara bayi sejak dini. Prevalensi keterlambatan bicara diperkirakan sekitar $3-10 \%$ di seluruh dunia. Pemberian ASI eksklusif dari tahun ke tahun terus menurun, padahal ini salah satu rangsangan secara dinamis, interaktif, dan kompleks yang melibatkan Visual-Auditori-Kinetik. Proses ini berpengaruh pada kinerja kognitif. Tujuan pengabdian masyarakat ini adalah untuk mengetahui dampak pengetahuan akan manfaat ASI terhadap kemampuan biacara pada bayi 0-24 minggu pada ibu-ibu posyandu Menur I dan IX Kelurahan Makamhaji. Metodelogi pengabdian masyarakat ini berupa ceramah dan diskusi. Pengukuran qusioner serta pengukuran deteksi dini perkembangan bicara dengan Early Language Milestone Scale-2 (ELMS-2). Teknik analisis data deskriptif. Hasil dan Pembahasan kegiatan pengabdian masyarakat dihadiri kader dan ibu-ibu sejumlah 45 orang dengan rentang usia 21 sampai dengan 40 tahun. Pada ibu menyusui sejumlah 35 bayi, nilai rata rata pre tes dan post tes maka ada peningkatan pengetahuan sebesar $32 \%$. Hasil karakteristik dari jenis kelamin laki-laki paling banyak 18 bayi $(51,4 \%)$, usia bayi didominasi kurang dari 25 minggu 30 bayi $(71,4 \%)$, hubungan ASI pengukuran blanko ELMS-2 normal 10 bayi (28,6\%), bayi yang menyusui langsung ASI dari ibunya lebih baik dalam mencengah keterlambatan bicara. Ada dampak peningkatan pengetahuan pada akan manfaat asi dalam membantu merangsang kemampuan dalam bicara bayi usia 24 minggu. deteksi dini ELMS-2 katagori normal ada 10 bayi perkembangan bicaranya
\end{abstract}

Kata Kunci: ASI, ELMS-2, Bayi 24 Minggu

\begin{abstract}
Visual stimulation is very close to the baby's ability to speak from an early age. The prevalence of speech delay is estimated at about 3-10\% worldwide. Exclusive breastfeeding from year to year continues to decline, but this is one of the dynamic, interactive, and complex stimuli involving VisualAuditori-Kinetik. This process affects cognitive performance. The purpose of community service is to know the impact of knowledge on the benefits of breastfeeding biochemical abilities in infants 0-24 weeks in mothers posyandu Menur I and IX Kelurahan Makamhaji. Community service method is in the form of lectures and discussions. Qusioner measurements as well as measurement of early detection of speech development with Early Language Milestone Scale-2 (ELMS-2). Descriptive data analysis techniques. Results and Discussion of community service activities attended by cadres and mothers of 45 people with age range 21 to 40 years. In breastfeeding mother of 35 babies, the mean score of pre test and post test then there is a knowledge increase of $32 \%$. The results of the characteristics of the male sex were at most 18 infants (51.4\%), infant age was dominated less than 25 weeks 30 babies (71.4\%), breastfeeding relationship measurements of normal ELMS-2 10 infants $(28.6 \%)$, a baby who breastfed directly from her mother's milk better in the midst of delayed speech. There is an increased impact of knowledge on the benefits of breastfeeding in helping to stimulate the ability to talk 24-week-old babies. early detection of ELMS-2 normal category there are 10 baby speech development
\end{abstract}

Keywords: Breastfeeding, ELMS-2, Baby 24 Weeks 


\section{PENDAHULUAN}

Perbedaan pada tiap individu bayi dalam kemampuan visual sangat terkait akan perkembangan bahasa dan kinerja kognitif. Hal ini mencerminkan perkembangan perhatian, yang berasal dari kontrol perhatian eksogen dan endogen pada bulan pertama kehidupan bersamaan perubahan dan perkembangan korteksnya (bidang mata depan, korteks parietal, dan korteks prefrontal). [1][2]

Jika rangsangan durasi secara dinamis, interaktif, dan kompleks serta lebih lama pada habituasi bayi akan ada premosesan dalam kecepatan memori. Adanya perubahan keterampilan, perhatian bayi menunjukkan peningkatan kapasitasnya dalam pengkodean informasi contohnya: saat punting susu ibu didekatkan pda mulutnya secara langsung mengalihkan perhatian aktivitas, irama detak jantung dan fokus visual menunjukkan perhatian yang terus menerus.[3] Pola Penafsirkan seperti ini ada indikasi hubungan keterlibatan perhatian dan pemrosesan informasi optimal erat hal konsanan (vokal) serta mencakup lebih luas dan lebih tinggi dalam kemampuan kognitif pada masa tersebut.[1][4] Komunikasi linguistik yang berarti merupakan tonggak penting saat bayi mulai mengerti dan kemudian menghasilkan suara bahasa mereka.

Identifikasi penundaan kemampuan bicara menurut Komnas Penanggulangan Gangguan Pendengaran dan Ketulian (PGPKT) Indonesia tahun 2011, prevalensi keterlambatan bicara sekitar 3-10\%. Ini menjadi upaya promotif dan preventif serta edukatif pada masyarakat khususnya ibu-ibu yang memiliki bayi, serta menjadi perhatian dan deteksi dini akan hal tersebut mencakup jalur perkembangan bahasa yang kompleks serta memiliki relevansi. Kemampuan terbentuk melalui proses gerak refleks merupakan kemampuan khusus yang dimiliki oleh bayi sejak lahir berupa pergerakan spontan yang aktif. Refleks primitif bayi akan dipergunakan sampai sepanjang kehidupan (long life refleks). [5] Refleks ini merupakan gerakan involuntary tidak terkontrol. Refleks digunakan untuk mendeteksi secara dini penyimpangan tumbuh kembang.[6][5]

Refleks Morro akan berangsur menghilang biasanya usia 5 bulan, sedangkan refleks yang berubah jadi terkendali adalah refleks rooting dan sucking.[5] Fungsinya pun jadi berkembang, yaitu kemampuan untuk minum dan feeding.[5][7] Feding mempunyai beberapa fungsi, yaitu kemampuan mengunyah dan menelan, serta halyang tidak terlalu penting adalah kemampuan komunikasi. Refleks rooting merupakan refleks diamana bayi mencari putting susu ibu, sedangkan reflex sucking merupakan reflex menghisap yang muncul saat bayi minum ASI.[8] Setelah bayi berusia 1 bulan, tangisan atau suaranya mulai berbeda, namun masih dikategorikan dalam refleks. Kesan bunyi tangisan-tangisan bayi tersebut mirip dengan bunyi-bunyi vokal (oeee...ooaaa), yang disebut dengan suara reflex atau Reflexive Vocalization. [6][1][8] Pada usia 1 bulan, bayi mengeluarkan bunyi yang diulang-ulang tetapi ini masih tergolong refleks.

Pemeriksaan ELMS-2 dapat membedakan keterlambatan bicara akibat gangguan pendengaran. Menurut Coplan dkk telah menguji sensitifitas dan spesifisitas ELMS dengan hasil cukup baik yaitu $97 \%$ dan $93 \%$.dapat digunakan sebagai uji tapis kelompok risiko rendah maupun risiko tinggi, kelompok dengan cacat fisik, serta dapat pula mendeteksi keterlambatan bicara.[9]

Sedangkan kegiatan pengabdian masyarakat secara spesifik tujuannya adalah sebagai berikut: Mengetahui Dampak Pengetahuan Akan Manfaat ASI Terhadap Kemampuan Biacara Pada Bayi 0-24 Minggu Pada Ibu-Ibu Posyandu Menur I Dan IX Kelurahan Makamhaji. 


\section{METODOLOGI}

Kegiatan dilaksbayian pada tanggal 15 Desember 2016 di Kontor Aula Kelurahan Makamhaji. Ceramah dan diskusi diberikan berupa materi dampak menyusui ASI terhadap upaya merangsang kemampuan. Kegiatan tersebut dilanjutkan dengan pemeriksaan dan deteksi dini dengan Blanko ELMS-2 pada bayi oleh staf dosen Fisioterapis Program Studi Fisioterapi Fakultas Ilmu Kesehatan UMS yang ahli dalam bidang Fisioterapi Pediatri..

Kegiatan P2M ini melibatkan instansi Program Studi Fisioterapi Fakultas Ilmu Kesehatan UMS dan Kader Posyandu, Ibu-Ibu yang menyusui Menur I dan IX Kelurahan Makamhaji yang terlibat ini mendapat keuntungan secara bersama sama (mutual benefit). Khalayak yang dijadikan sasaran kegiatan ini adalah Posyandu Menur I dan IX Kelurahan Makamhaji yang berusia antara 21 tahun sampai dengan 40 tahun. Evaluasi sejauh mana program ini terlaksana yang meliput:

1. Dilakukan pre tes dan pos tes mengenai , materi yang diberikan menyangku apa yang diinformasikan saat ceramah, tanya jawab maupun diskusi

2. Dilakukan deteksi dini dengan Pemeriksaan ELMS-2 Pada Posyandu Menur I dan IX Kelurahan Makamhaji

Data hasil tes baik pre test maupun post tes tentang pengetahuan pada akan manfaat asi dalam membantu merangsang kemampuan dalam bicara bayi usia 24 bulan dan hasil pemeriksaan ELMS-2 dianalisis dengan tehnik analisis diskriptif.

\section{HASIL DAN PEMBAHASAN}

Keberhasilan pelaksanaan kegiatan ini adalah para peserta pelatihan yang terdiri dari ibu ibu yang berusia antara 21 hingga 40 tahun sebanyak 45 Ibu-Ibu Posyandu Menur I dan IX Kelurahan Makamhaji memiliki pengetahuan dan pemahaman yang meningkat tentang pengetahuan akan manfaat ASI dalam membantu merangsang kemampuan dalam bicara bayi usia 24 minggu, Hal ini terlihat dari saat diskusi tanya jawaban adanya antusias atas keingintahuan hal tersebut.

Tabel 1.1 Pre dan pos tes Pengetahuan Pada Akan Manfaat Asi Dalam Membantu Merangsang Kemampuan Dalam Bicara Bayi Usia 24

\begin{tabular}{ccc}
\hline Ibu-ibu Posyandu & Pre & Post \\
\hline 45 & 270 & 357 \\
Rata-rata & 6,3 & 8,3 \\
\hline
\end{tabular}

Kemampuan para peserta dalam memahami tentang keterlambatan pada bayi serta dilanjutkan dengan deteksi dini kemampuan bayi dalam bentuk penilaian perkembangan bicara dengan menggunakan blangko Early Language Milestone Scale-2 (ELMS-2). Hal ini terlihat dari kemampuan ibu-ibu dalam menjawab pre tes dan pos tes soal tentang tersebut. Hasil yang dicapai pada post tes menunjukkan adanya peningkatan pencapaian skor dalam menjawab soal. Pada awal ada seorang ibu yang mendapatkan skor 4 karena hanya mampu menjawab empat buah pertanyaan tetapi saat post tes dilakukan ibu tersebut telah dapat menjawab 7 soal atau memiliki skor 7,0. Secara umum dapat dikatakan bahwa jika dibandingkan antara nilai rata rata pre tes dan post tes maka ada peningkatan sebesar 32 $\%$ hal ini dapat dihitung dengan jalan membandingkan antara nilai rata rata pre tes sebesar 6,30 dan hasil post tesr sebesar 8,30. 

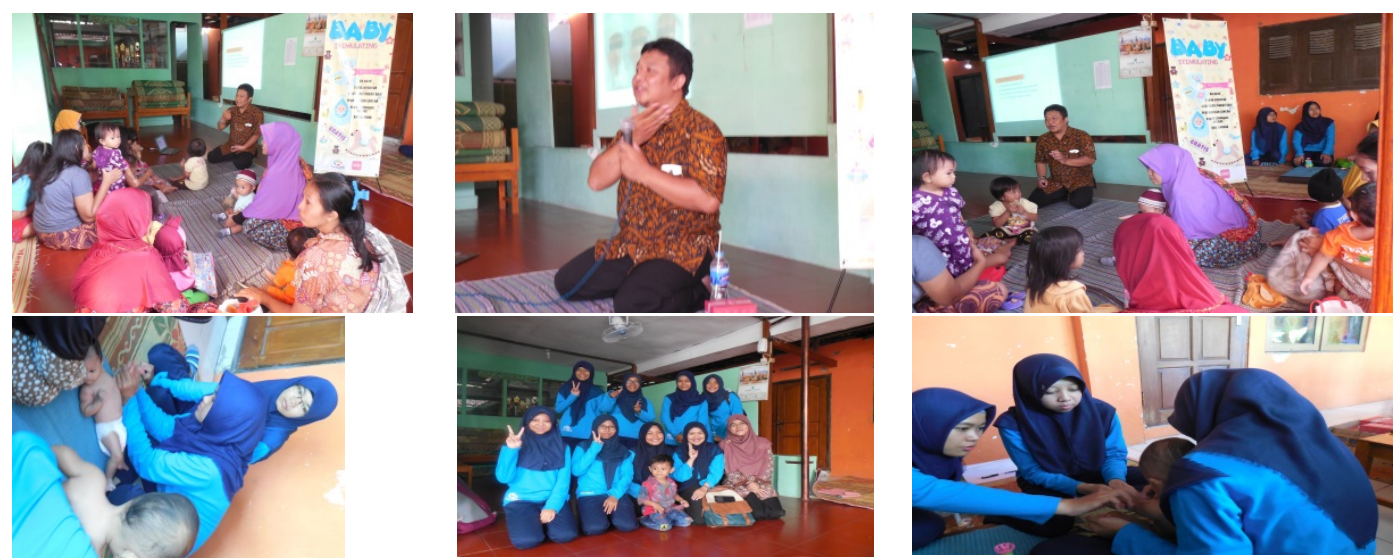

Dokumentasi kegiatan pengabdian masyarakat di Posyandu Menur I

Prosentase kenaikan hasil test yang relatif besar 32\% ini disebabkan karena secara umum, tingkat pengetahuan dari ibu ibu adalah tamatan sekolah menengah pertama. Penambahan pengetahuan tidak semuanya di serap dalam waktu singkat, perlu pemberian pengetahuan ulang lagi agar pengetahuan tersebut dapat meningkat secara maksimal. Akan tetapi dengan ketekun mendengarkan apa yang diuraikan oleh narasumber dan mencatat hal hal yang mereka belum pahami.

Disamping itu, respon yang sangat positif terhadap kegiatan ini juga diberikan oleh peserta. Ini terlihat dari pertanyaan yang peserta utarakan saat diskusi. Beberapa contoh pertanyaan yang mereka lontarkan adalah mengapa ASI bisa merangsang dalam upaya kemampuan bayi bicara dan masih banyak pertanyaan lain sekitar ASI dan faktor-faktor gangguan ketelambatan bicara pada bayi.

Pada saat diskusi dimana salah satau faktornya teraktifasi refleks sucking atau menghisap dinama lidah bergerak kesegala penjuru arah, respon ini yang menjadi dasar nantinya dalam membentuk suara-suara atau konsonan tahap berikutnya. Pertanyaan pertanyaan ini mengindikasikan bahwa ibu ibu mengetahui apa yang diberikan oleh narasumber dan merupakan hal yang positif. Dalam perilaku "tahu" menyatakan memiliki proses panjang yang berurutan yakni kesadaran, merasa tertarik, menimbang-nimbang, uji coba, dan adopsi. Pada tahapan adopsi ini proses perilaku individu disesuaikan dengan pengetahuan, kesadaran, dan sikap terhadap suatu objek, sehingga terbentuklah sebuah kebiasaan. [6]

Distribusi responden berdasarkan usia sebagian besar usia kurang dari 25 minggu berjumlah 30 bayi (71,4\%), sedangkan usia lebih dari 24 minggu berjumlah 10 bayi (24,6\%).

Tabel 2. Karakteristik Bayi berdasarkan Usia

Keterangan Jumlah Prosenrase

\begin{tabular}{ccc}
\hline Usia Bayi & & \\
Kurang dari 24 minggu & 25 & $71,4 \%$ \\
\hline
\end{tabular}




\begin{tabular}{ccc}
\hline Lebih dari 24 minggu & 10 & $24,6 \%$ \\
total & 35 & $100 \%$ \\
\hline
\end{tabular}

Bayi usia kurang 24 minggu mengelurkan suara berupa mono babbling (ba..da..ga) sedangkan lebih dari 24 minggu mengalami suara item yang keluar adalah polysylabic babbling (bababa...lalala).

Buyi babbling terbentuk dari bunyi konsonan dan vokal yang disuarakan dengan durasi panjang, pendek maupun diulang-ulang. Kemampuan bunyi babbling yang pertama adalah /pa/ dan /ba/, sangat erat kaitannya dengan reflek menyusui. Sensasi sentuhan terhadap bibir atas dan bibir bawah secara tidak sengaja membentuk kombinasi /a/, sedangkan kombinasi /ga/ terbentuk dari gerakan menelan, $/ \mathrm{m} /$ terbentuk dari pertemuan bibir atas dan bibir bawah. Keterlambatan dalam babbling bisa dikarenakan kurangnya stimulasi dari orang sekitar, bayi dilatih untuk berbicara dengan intonasi naik turun dan ekspresif agar mudah dipahami. Babbling merupakan fondasi berbahasa, dimana bayi akan mentransformasikan suara atau kata-kata yang didengarnya untuk diselaraskan dengan kemampuan bicara.

\section{Tabel 3. Karakteristik Bayi berdasarkan dan Hasil Pengukuran ELMS-2

Keterangan Jumlah Prosenrase

\begin{tabular}{lcc}
\hline \multicolumn{2}{l}{ Jenis Kelamin } & \\
Laki-laki & 18 & $51,4 \%$ \\
Perempuan & 17 & $48,6 \%$
\end{tabular}

Hasil Pengukuran ELMS-2

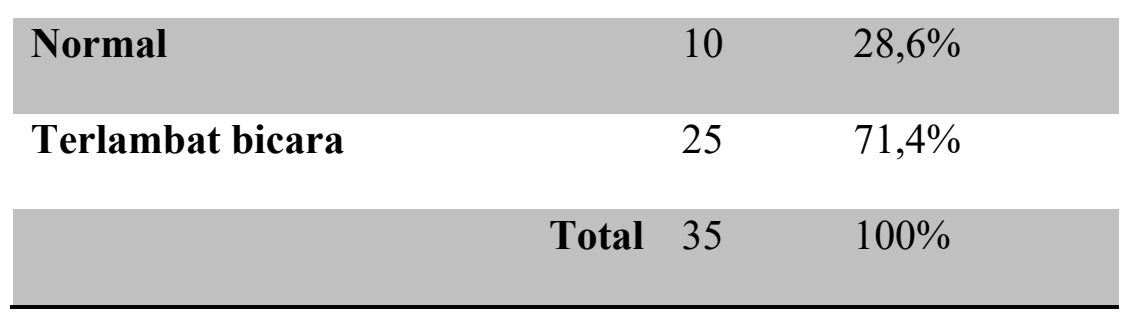

Berdasarkan jenis kelamin sebagian besar adalah laki-laki berjumlah 18 bayi $(51,4 \%)$, sedangkan perempuan berjumlah 17 bayi $(48,6 \%)$. Jenis kelamin laki-laki bayi terlambatan bicara $(71,4 \%)$, rasio laki-laki dibanding perempuan antara $8: 1$. Hal ini saat janin laki-laki hormon testosteron 10 kali lebih banyak daripada perempuan ketika didalam kandungan, hormon ini berperan penting dalam proses perkembangan otak.[2]

Hasil pengukuran dimana bayi dengan riwayat menyusui ASI berjumlah 10 bayi $(28,6 \%)$ dan di dalam pengukuran menurut ELMS-2 normal. Ada yang mengalami keterlambatan bicara berjumlah 25 bayi (71\%) dimana riwayat menyusui ASI dan kombinasi dot (pacifier). Resiko keterlambatan bicara meningkat jika interaksi fisiologi kompleks yang berkaitan dengan pernapasan, laring dan struktur oral.[9] Pengetahuan akan proses menyusui dengan ASI diikuti kesadaran positif pada suatu objek maka akan mengahasilkan perilaku yang langgeng namun sebaliknya jika pengetahuan tidak diikuti kesadaran, maka perilaku 
yang dihasilkan pun akan bersifat sementara.[9][2] Proses menyusui akan meningkatkan hubungan atau ikatan batin antara ibu dan bayi. Ikatan batin sangat penting dalam menentukan perilaku bayi dikemudian hari. [8]

Menstimulasi perkembangan otak bayi, serta merangsang kedekatan antara ibu dan bayi. Dekapan ibu akan memenuhi kebutuhan emosi bayi (asih) melalui kontak fisik pada punting susu dan mulut, lidah serta psikis akan rasa tenang dengan secara lansung kontak visual-auditori dan penciuman. [8] Sebagai contoh seorang ibu mengajak berbicara dengan penuh kasih sayang, ini akan memenuhi stimulasi mental secara dini bayi dan secara tidak langsung memenuhi kebutuhan psikologis ibu. Proses ini tidak terdapat pada bayi yang diberikan dengan dot (pacifier).

\section{KESIMPULAN}

Kesimpulannya terdapat ada dampak peningkatan pengetahuan pada akan manfaat asi dalam membantu merangsang kemampuan dalam bicara bayi usia 24 minggu. deteksi dini ELMS-2 katagori normal ada 10 bayi perkembangan bicaranya. Saranya kepada orang tua dan masyarakat hendaknya memberikan ASI eksklusif dan lebih memperhatikan perkembangan bicara bayinya

\section{UCAPAN TERIMAKASIH}

Pengabdian ini merupakan bagian instansi Program Studi Fisioterapi Fakultas Ilmu Kesehatan UMS dan Ibu-Ibu Posyandu Menur I dan IX Kelurahan Makamhaji

\section{DAFTAR PUSTAKA}

[1] R. E. Eilers and D. K. Oller, "Infant vocalizations and the early diagnosis of severe hearing impairment," J. Pediatr., vol. 124, no. 2, pp. 199-203, 1994.

[2] E. Dupoux, "Language , Brain , and Cognitive Development."

[3] S. T. Kover, L. M. Mccary, A. M. Ingram, D. D. Hatton, and E. Roberts, "Fragile X Syndrome: Change over Time and the Role of Attention," vol. 120, no. 2, pp. 125$144,2017$.

[4] L. A. Chiarello et al., "Family Priorities for Activity and Participation of Children and Youth With Cerebral Palsy," Phys. Ther., vol. 90, no. 9, pp. 1254-1264, 2010.

[5] Y. Futagi, Y. Toribe, and Y. Suzuki, "The Grasp Reflex and Moro Reflex in Infants: Hierarchy of Primitive Reflex Responses," Int. J. Pediatr., vol. 2012, pp. 1-10, 2012.

[6] S. Nathani and D. K. Oller, "Beyond ba-ba and gu-gu: Challenges and strategies in coding infant vocalizations," Behav. Res. Methods, Instruments, Comput., vol. 33, no. 3, pp. 321-330, 2001.

[7] H. McConachie et al., "Systematic review of tools to measure outcomes for young children with autism spectrum disorder," Health Technol. Assess. (Rockv)., vol. 19, no. 41, pp. 1-538, 2015.

[8] E. Flak, I. Kaim, I. Lisowska-miszczyk, and A. Skarupa, "Effect of Exclusive Breastfeeding on the Development of Children 'S Cognitive Function in the," vol. 171, no. 1, pp. 151-158, 2013.

[9] M. Maddeppungeng, "Penilaian Early Language Milestone Scale 2 (Elm Scale 2) Pada Anak dengan Keterlambatan Bicara," vol. 9, no. 2, pp. 93-99, 2007. 